\title{
OBSERVAÇÕES SOBRE A TRANSMISSÃO DA LEISHMANIOSE TEGUMENTAR NO ESTADO DE SÃO PAULO, BRASIL
}

\author{
Oswaldo Paulo Forattini* \\ Ernesto Xavier Rabello * \\ Oswaldo Pinto Serra** \\ Maria das Dores Cotrim* \\ Eunice Aparecida Bianchi Galati * \\ José Maria Soares Barata*
}

RSPU-B/297

ForatirinI, O. P. et al. - Observações sobre a transmissão de leishmaniose tegumentar no Estado de São Paulo, Brasil. Rev. Saúde públ., S. Paulo, 10:31-43, 1976.

Resumo: Em dois focos de leishmaniose tegumentar do Estado de São Paulo, Brasil foram levadas a efeito observaçôes destinadas a verificar o comportamento da fauna flebotominica local. Os resultados evidenciaram a dominância de Psychodopygus intermedius $e$ sua freqüência ao ambiente humano, representado pelo domicílio e peridomicilio. Tais aspectos, aliados aos fatos já conhecidos, permitem apontar essa espécie como transmissora e preconizar a aplicação domiciliar de inseticidas de poder residual como método profilático.

UnITERMos: Leishmaniose tegumentar. Transmissão. Psychodopygus intermedius. Flebotomineos (comportamento, invasão de domicilios). Epidemiologia.

\section{INTRODUCAO}

A recente constatação de endemia ativa de leishmaniose tegumentar no Estado de São Paulo veio, novamente, trazer problema epidemiológico que se supunha não mais existente nessa região do Brasil. Tanto em focos isolados no interior, como em áreas mais extensas do litoral, a ocorrência de casos humanos tem alertado para a necessidade de maiores estudos na procura de possível método preventivo (Forattini e col. ${ }^{3,7}$, 1972, 1973). Nesse sentido, reveste-se de maior importância a determinação do modo de transmissão, ou seja, cumpre esclarecer qual ou quais seriam os possiveis flebotomíneos transmissores. E, ao lado disso, as características que lhes permitiriam o relacionamen com a população humana local e daí veicular-lhe a parasitose.

Algum esclarecimento já foi obtido ao se constatar, em um dos focos estudados, a infecção natural de Pintomyia pessoai e de Psychodopygus intermedius com cepas que se mostraram patogênicas para

- Do Departamento de Epidemiologia da Faculdade de Saúde Pública da USP - Avenida Dr. Arnaldo, 715 - São Paulo, SP - Brasil.

* Do Departamento de Parasitologia do Instituto de Ciencias Blomédicas da USP Cidade Universitária - São Paulo, SP - Brasil. 
FORATTINI, O. P. et al. - Observações sobre a transmissão de leishmaniose tegumentar no Estado de São Paulo, Brasil. Rev. Saúde públ., S. Paulo, 10:31-43, 1976.

animais de laboratório (Forattini e col. ${ }^{5}$, 1972). Ao mesmo tempo, foi possível demonstrar, na mesma localidade representada pela Fazenda Jataí, a presença de foco enzoótico, mediante o isolamento de cepas de roedores silvestres Akodon e Oryzomys, ali capturados (Forattini e cols. ${ }^{ \pm, 6}, 1972,1973$ ).

Face a tais encontros, encetaram-se várias observações destinadas a evidenciar quais seriam os principais fatores na transmissão da leishmaniose tegumentar à população humana. Como se referiu, os objetivos principais foram a identificação das espécies de Phlebotominae que, pelo seu comportamento, pudessem ser epidemiologicamente responsabilizadas.

\section{MATERIAL E MÉTODOS}

As investigações foram levadas a efeito nos dois focos já assinalados anteriormente (Forattini e col. ${ }^{3,7}$, 1972, 1973). Um deles foi representado por área florestal residual da Fazenda Jataí, no município de Luís Antônio, Estado de São Paulo (Forattini e col. ${ }^{4}, 1972$ ). O segundo foi localizado no Bairro de São Lourencinho, do mesmo Estado que é constituído por conjunto de propriedades rurais dispostas ao longo do vale do rio de mesmo nome, no município de Pedro de Toledo. Enquanto o primeiro representa um foco do interior do Estado de São Paulo, o segundo pertence à área endêmica formada pelo conjunto do ecossistema litorâneo da Serra do Mar. Assim, pois, os procedimentos, para as duas localidades, foram as seguintes:

Fazenda Jataí - As observações no ambiente florestal basearam-se nas coletas de formas aladas e executadas de três maneiras. A primeira constitui na realização de uma captura semanal com o emprego de armadilha tipo Shannon, dotada de isca luminosa, e operando no horário das 18:00 às 21:00 horas. As outras duas foram levadas a efeito de maneira não sistemática e tiveram apenas o obje- tivo de verificar possíveis diferenças de composição específica em dois níveis da floresta correspondentes ao solo e à copa arbórea. Para isso, construiram-se seis plataformas em árvores previamente escolhidas. Em cada uma delas, e por rodízio, realizaram-se capturas concomitantes no nível alto e no baixo, com isca humana e de duração variável dentro do horário das 18:00 às 21:00 horas. Ao lado dessas, outra série de coletas foram executadas nessas mesmas plataformas, com o emprego de armadilhas tipo Disney, colocadas nos dois níveis e pelo espaço de uma semana cada vez. Com tais métodos pretendeu-se observar possiveis variações na composição da fauna flebotomínica local e a influência do tipo e do local de coleta. Dessa maneira, seria possível obter dados que permitissem levantar hipóteses sobre as atividades desses dípteros relacionadas com os reservatórios da infecção leishmaniótica ali existente.

Quanto ao ambiente domiciliar, as características locais da Fazenda Jataí, não possibilitaram maiores escolhas. Por conseguinte, foi utilizada a única habitação existente na área e situada a cerca de $200 \mathrm{~m}$ da floresta. Nessa casa foram levadas a efeito duas coletas mensais, a intervalos regulares, com a utilização do horário das 18:00 às 21:00 horas.

Bairro de São Lourencinho - No ambiente extradomiciliar foram feitas coletas mediante também o emprego de armadilha tipo Shannon dotada de isca luminosa. Com o objetivo de observar a composição da fauna flebotomínica, levaram-se a efeito capturas em caráter não regular e em vários pontos do nível inferior do meio florestal da localidade. Para cada captura foram dispendidas duas horas escolhidas aleatoriamente, na primeira metade do período noturno. Outro tipo de coleta foi levado a efeito, em dias escolhidos, para abranger todas as primeiras horas da noite ou a totalidade de seu decurso. A escolha desses dias foi orientada pelas condições presentes de tempe- 
FORATTINI, O. P. et al. - Observações sobre a transmissão de leishmaniose tegumentar no Estado de São Paulo, Brasil. Rev. Saúde públ., S. Paulo, 10:31-43, 1976.

ratura e de umidade, quando se aproximassem do considerado ótimo para a atividade desses insetos, ou seja, ao redor de $20^{\circ} \mathrm{C}$ e acima de $90 \%$, respectivamente.

Quanto ao domicílio, procedeu-se de maneira análoga à acima descrita para as observações extradomiciliares. Assim, as coletas foram realizadas manualmente e de dois tipos. I'm deles foi levado a efeito em várias habitações locais, de maneira não regular e ocupando, cada vez, duas horas variavelmente situadas na primeira metade da noite. 0 outro foi conduzido de forma a poder observar toda a primeira metade ou a totalidade do período noturno. À semelhança de no ambiente florestal, pretendeu-se verificar a composição da fauna visitante e o seu comportamento durante as horas da noite.

Finalmente, realizou-se certo número de coletas no peridomicílio com o emprego da armadilha de Shannon e isca luminosa. Entendeu-se como ambiente peridomiciliar aquele na imediata vizinhança das habitações e onde geralmente são instalados anexos como galinheiros e outros abrigos de animais domésticos.

\section{R ESULTADOS}

Os dados observados para os dois focos foram os seguintes:

\section{Fazenda Jataí}

- Ambiente florestal - No período de $1 .^{\circ}$ de maio a 30 de novembro de 1973 foram realizadas 31 coletas com armadilha de Shannon correspondentes a outras tantas semanas, num total de 186 horas/ homem. Os resultados obtidos constam da Tabela 1, verificando-se a absoluta dominância de Psychodopygus intermedius nesse período e tipo de captura. De maneira geral, e seguindo aspecto característico dos flebotomíneos, as variações foram muito acentuadas pois as médias horárias oscilaram desde o zero até um máximo de 27,0, com valor global de 8,5 .

As coletas nos dois niveis florestais, ou sejam, do da copa arbórea e do solo, for- neceram os resultados constantes da $\mathrm{Ta}$ bela 2 e correspondentes ao período de maio a dezembro de 1973. Pôde-se evidenciar a presença ainda dominante do $P s$. intermedius em ambos níveis parecendo haver maior freqüência no solo florestal. Por sua vez, os dados obtidos com as armadilhas tipo Disney, além de sugerirem esse aspecto, forneceram número preponderante de machos, o que, como se poderia prever, não ocorreu com as outras capturas.

- Ambiente domiciliar - As observações foram executadas no período de fevereiro a novembro de 1973 , com o total de 120 horas/homem trabalhadas. Os resultados estáo apresentados na Tabela 3 e por eles pode-se verificar a presença exclusiva do Psychodopygus intermedius. As médias horárias foram bastante variáveis, dentro de faixa que se extendem desde o valor praticamente nulo até o máximo obtido de 47,4 . A média horária total correspondeu a 15.8 , o que representa valor a ser levado em conta, especialmente em se tratando de ambiente domiciliar.

\section{Bairro São Lourencinho}

- Ambiente florestal - Os dados apresentados na Tabela 4 mostram a composição da fauna de flebotomíneos obtida no nivel inferior da floresta, com 58 horas/ homem trabalhadas de maneira não regular, no período de outubro de 1973 a novembro de 1974. Pode-se verificar que, pelo menos com esse procedimento, ocorre predominância praticamente absoluta de Psychodopygus intermedius. A essa espécie correspondeu média horária total de 13,5, dominando assim completamente o aparecimento dos outros representantes, que foi muito discreto com esse tipo de captura.

As coletas continuadas foram em número de duas. L'ma abrangeu todo o período noturno e foi iniciada às 18:00 horas de 30 de abril de 1974 e terminou 
FORATTINI, O. P. et al - Observaçōes sobre a transmissão de leishmaniose tegumentar no Estado de Sáo Paulo, Brasil. Rev. Saúde públ., S. Paulo, 10:31-43, 1976.

às 6:00 horas do dia seguinte. $\mathrm{A}$ outra incluiu apenas o período das 20:00 às 24:00 horas do dia 18 de setembro do mesmo ano. Os resultados acumulados constam da Tabela 5 podendo observar-se o predomínio de Ps. intermedius, sobre as demais espécies representadas principalmente por Lutzomyia migonei e Pintomyia fischeri. Essa predominância é bem representada pela média horária total de 249.0 para 56 horas/homens trabalhadas. A sua flutuação nas várias horas do período mostra maiores valores naquelas correspondentes à primeira metade da noite (Fig. 1).

- Ambiente domiciliar e peridomiciliar - Os resultados obtidos nas coletas não regulares acham-se resumidos na Tabela 6 . Pôde-se observar a predominância de Psychodopygus intermedius em ambos os ambientes, praticamente constituindo a totalidade da fauna flebotomínica que os frequientam. As médias horárias totais foram de 7,6 para o primeiro e 127.7 para o segundo.

As coletas ininterruptas foram em número de quatro. Duas incluiram todo o período noturno com início às 18:00 horas dos dias 12 de março e 2 de abril de 1974 e terminando às $6: 00$ horas dos dias seguintes respectivos. As outras compreenderam os períodos de 20:00 horas de 18 de fevereiro a 1:00 hora do dia seguinte e de 19:00 às 24:00 horas do dia 11 de abril do mesmo ano. Os resultados são apresentados, de maneira acumulada na Tabela 7 , onde pode-se verificar a frequiência do $P$ s. intermedius à habitação com certa tendência a atingir o máximo depois da meia noite (Fig. I) e decréscimo acentuado no período da madrugada que imediatamente antecede o nascer do sol.

\section{COMENTARIOS}

Os dados conseguidos na floresta da Fazenda Jataí com a armadilha de Shannon mostraram bastante irregularidade no comparecimento do Psychodopygus inter- medius, embora as coletas tivessem sido feitas de maneira sistemática durante 31 semanas e essa espécie comparecesse de forma praticamente exclusiva (Tabela 1). 0 número de capturas negativas certamente encontrará explicação na ocorrência de condiçôes desfavoráveis de temperatura e umidade por ocasião da realização dessas coletas improdutivas. De qualquer maneira, ao lado do comportamento irregular, notou-se a absoluta dominância da espécie.

Aspecto semelhante resultou das coletas nos dois níveis florestais (Tabela 2). Como se verificou, a dominância se manteve e o flebotomíneo pareceu preferir os níveis baixos. A maior proporção de machos obtidos com as armadilhas tipo Disney sugerem a possível presença dos criadores dessa espécie nesse nível do ambiente florestal.

No ambiente domiciliar os valores obtidos também apresentaram acentuada variação (Tabela 3 ). Chamou a atenção os níveis alcançados serem, em alguns casos, maiores do que os da coleta florestal. e refletidos nas médias horárias globais que foram de 15,8 para o domicílio e 8,5 para a armadilha tipo Shannon. Isso poderá sugerir a possível tendência da população local de $P$ s. intermedius de invadir as casas, não apenas na procura do exercício da hematofagia, como também para encontrar abrigo. Em outros termos, tornase lícito levantar a hipótese de certo hábito domiciliar em desenvolvimento nesse foco.

Os resultados obtidos no Bairro de São Lourencinho evidenciam também o papel do Psychodopygus intermedius na veiculação da endemia. Nas coletas em ambiente florestal essa espécie foi absolutamente dominante. Embora tais capturas não tivessem sido feitas de maneira regular, elas foram distribuídas durante período longo compreendido entre outubro de 1973 e novembro de 1974 e a média horária total obtida foi bastante sugestiva da dominância desse flebotomíneo (Tabela 4). É conhecida a irregularidade com que 
FORATTINI, O. P, et al. - Observações sobre a transmissão de leishmaniose tegumentar no Estado de São Paulo, Brasil. Rev. Saúde públ., S. Paulo, 10:31-43, 1976.

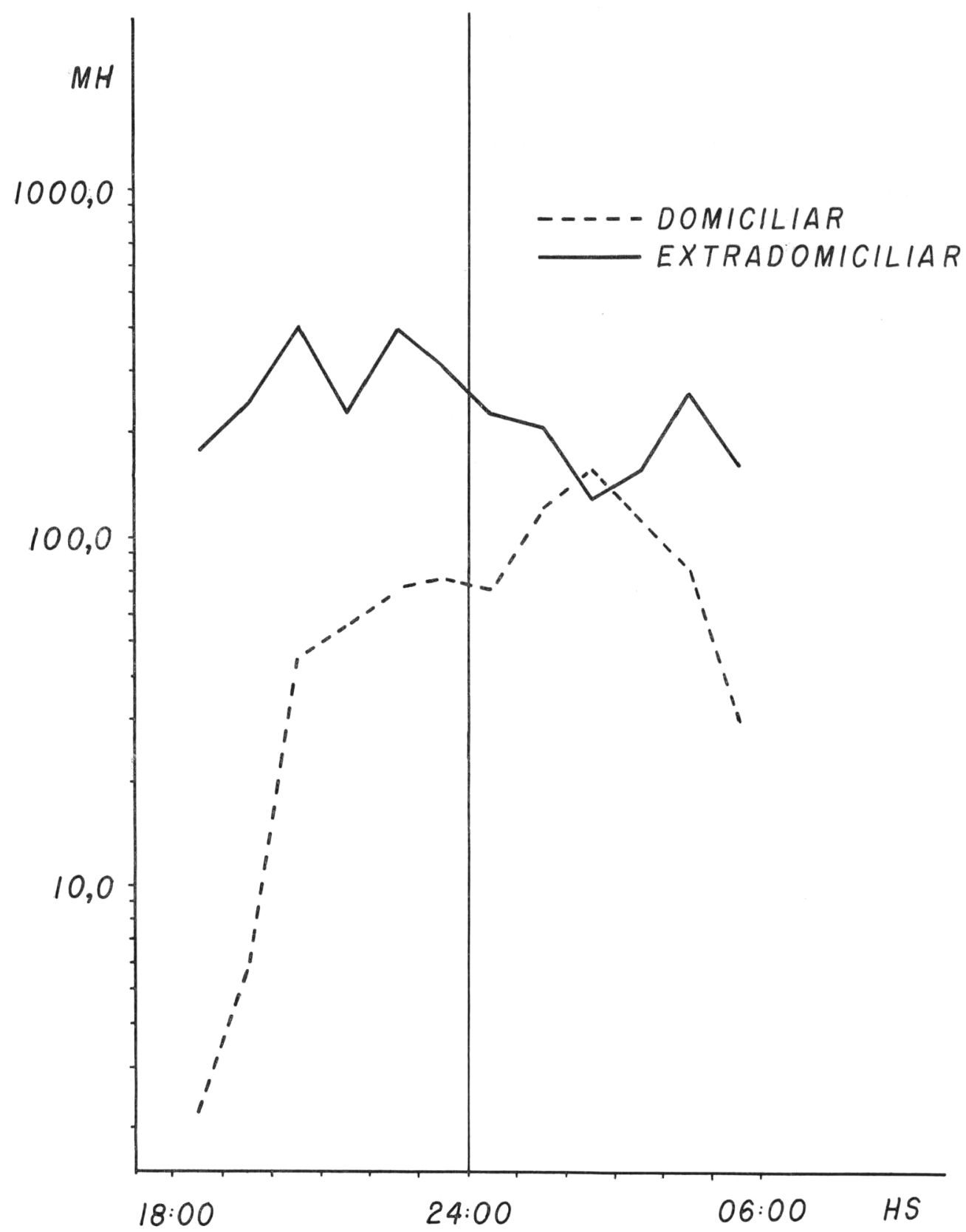

Fig. 1 - Variações das médias horárias (MH) observadas com Psychodopygus intermedius, nos ambientes domiciliar e extradomiciliar (silvestre), durante o periodo noturno compreendido entre as 18:00 e 6:00 horas (HS). 
FORATTINI, O. P. et al. - Observaçōes sobre a transmissão de leishmaniose tegumentar no Estado de São Paulo, Brasil. Rev. Saúde públ., S. Paulo, 10:31-43, 1976.

TABELA 1

Resultados das coletas semanais de flebotomíneos no ambiente florestal da Fazenda Jatal, com o emprego da armadilha tipo Shannon (malo a novembro 1973)*.

\begin{tabular}{|c|c|c|c|c|c|c|}
\hline \multirow{2}{*}{$\begin{array}{c}\text { Semanas } \\
(\mathrm{V}-\mathrm{XI}-1973)\end{array}$} & \multicolumn{4}{|c|}{ Psychodopygus intermedius } & \multirow{2}{*}{ Outras espécies } & \multirow{2}{*}{$\mathbf{T}$} \\
\hline & 우 & $\sigma^{2} \sigma^{+}$ & $\mathbf{T}$ & $\mathrm{MH}$ & & \\
\hline $1 \mathrm{a}$ & 63 & 13 & 78 & 13,0 & & 78 \\
\hline $2 a$ & - & -- & - & - & & 一 \\
\hline $3 a$ & - & - & - & - & & - \\
\hline $4 a$ & 81 & 1 & 82 & 13,7 & 10 \& $q$ Pintomyia pessoai & 92 \\
\hline $5 a$ & 6 & 3 & 9 & 1,5 & & 9 \\
\hline $6 a$ & 一 & - & - & - & & - \\
\hline $7 a$ & 36 & - & 36 & 6,0 & & 36 \\
\hline $8 \mathrm{a}$ & 50 & 1 & 51 & 8,5 & & 51 \\
\hline $9 a$ & - & 一 & - & - & & - \\
\hline $10 \mathrm{a}$ & 97 & 4 & 101 & 16,8 & & 101 \\
\hline $11 \mathrm{a}$ & 155 & 7 & 162 & 27,0 & 1 \& Lutzomyia sp. & 163 \\
\hline $12 \mathrm{a}$ & 一. & - & 一 & - & & - \\
\hline $13 a$ & 一 & 一 & - & - & & 一 \\
\hline $14 a$ & 5 & - & 5 & 0,8 & & $\mathbf{5}$ \\
\hline $15 a$ & 142 & 3 & 145 & 24,2 & & 145 \\
\hline $16 a$ & 69 & 1 & 70 & 11,7 & & 70 \\
\hline $17 \mathrm{a}$ & 31 & 1 & 32 & 5,3 & & 32 \\
\hline $18 \mathrm{a}$ & 152 & 1 & 153 & 25,5 & & 153 \\
\hline $19 a$ & - & - & - & - & & - \\
\hline $20 a$ & 一 & 一 & 一 & - & & - \\
\hline $21 a$ & $一$ & 一 & 一 & - & & - \\
\hline $22 a$ & 49 & - & 49 & 8,2 & & 49 \\
\hline $23 a$ & 13 & 1 & 14 & 2,3 & & 14 \\
\hline $24 a$ & 3 & 二 & 3 & 0,5 & & 3 \\
\hline $25 a$ & 109 & 8 & 117 & 19,5 & & 117 \\
\hline $26 a$ & 86 & 5 & 91 & 15,2 & & 91 \\
\hline $27 a$ & 65 & 3 & 68 & 11,3 & & 68 \\
\hline $28 a$ & 12 & - & 12 & 2,0 & & 12 \\
\hline $29 a$ & 8 & - & 8 & 1,3 & & 8 \\
\hline $30 a$ & 152 & 1 & 153 & 25,5 & & 153 \\
\hline $31 a$ & 139 & 6 & 145 & 24,2 & & 145 \\
\hline$T$ & 1525 & 59 & 1584 & 8,5 & 11 & 1595 \\
\hline
\end{tabular}

* Médias horárias (MH) calculadas com 6 horas/homem para cada semana com o total de 186 horas/homem trabalhadas.

esses dípteros tendem a exercer sua atividade fazendo, em consequiência, de maneira mais explosiva do que rítmica. Face a isso, os resultados obtidos nas coletas que abrangeram as horas da primeira metade da noite e todo o período nolurno, evidenciaram melhor a atividade dessa espécie, como se pode verificar pela análise da Tabela 5. Como já se assinalou a análise desses dados permite verificar 
FORATTINI, O. P. et al. - Observações sobre a transmissão de leishmaniose tegumentar no Estado de São Paulo, Brasil. Rev. Saúde públ., S. Paulo, 10:31-43, 1976.

o amplo predomínio do flebotomíneo com maior presença na primeira metade da noite.

De maneira semelhante, o Ps. intermedius predominou nos ambientes domiciliar e peridomiciliar constituindo, praticamente, a única espécie visitante face à insignificância da representação de Lutzomyia migonei e Pintomyia fischeri (Tabela 6). Em condições favoráveis de temperatura e umidade, tende a invadir o domicílio durante todo o período noturno (Tabela 7).

Nessa oportunidade, as suas médias horárias apresentam variaçöes que sugerem aumento progressivo até as horas que se seguem à meia noite, passando a declinar de maneira acentuada, no período que antecede de imediato a aurora.

O gráfico que se observa na Fig. 1 mostra as curvas do possivel comportamento noturno desse flebotomíneo. Podese verificar que, na floresta a tendência parece ser o do aumento na primeira metade da noite e declínio na segunda. No domicílio, a ascensão da curva que se inicia nas primeiras horas da noite, ultrapassa as 24:00 horas invadindo a segunda metade do período, ocasião em que parece sugerir certo comportamento inverso ao que se observa no ambiente extradomiciliar. A explicação desse fenômeno talvez possa ser encontrada nos tipos de ecótopos. $\mathrm{Na}$ floresta, as coletas foram

TABEL 2

Resultados das coletas levadas a efeito na copa arbórea (CA) e no solo do ambiente florestal (SF) da Fazenda Jatai, com o emprego de isca humana e de armadilha tipo Disney (maio a dezembro 1973)*.

\begin{tabular}{|c|c|c|c|c|c|c|c|c|c|c|c|c|c|c|c|}
\hline \multirow{3}{*}{ Especies } & \multicolumn{8}{|c|}{ Isca humana } & \multirow{2}{*}{\multicolumn{6}{|c|}{$\underbrace{\text { Armadilha tipo Disney }}_{\mathrm{CA}}$}} & \multirow{3}{*}{$\mathrm{T}$} \\
\hline & \multicolumn{4}{|c|}{$\mathrm{CA}$} & \multicolumn{4}{|c|}{ SF } & & & & & & & \\
\hline & むむ & $00^{\circ}$ & $\mathbf{T}$ & $\mathrm{MH}$ & $\% \%$ & $0^{n} 0^{x}$ & $\mathbf{T}$ & MH & $9 \%$ & $8^{\circ} 0^{\prime \prime}$ & $\mathbf{T}$ & $q \%$ & $80^{\circ}$ & $\mathrm{T}$ & \\
\hline Brumptomyia & & & & & & & & & & & & & & & \\
\hline sp. & - & 一 & - & - & - & - & - & - & - & - & 一 & 1 & - & 1 & 1 \\
\hline Lutzomyia & & & & & & & & & & & & & & & \\
\hline firmatoi & - & - & 一 & 一 & 一 & - & 一 & $\rightarrow$ & - & 1 & 1 & 3 & 2 & 5 & 6 \\
\hline Pintomyia & & & & & & & & & & & & & & & \\
\hline pessoai & 13 & - & 13 & 0,4 & 25 & 1 & 26 & 0,8 & - & - & - & - & - & - & 39 \\
\hline Pressatia & & & & & & & & & & & & & & & \\
\hline choti & - & 一 & - & - & 一 & - & 一 & 一 & 一 & - & 一 & 1 & - & 1 & 1 \\
\hline Psychodopygus & & & & & & & & & & & & & & & \\
\hline intermedius & 97 & 3 & 100 & 2,8 & 168 & 5 & 173 & 4,9 & 5 & 14 & 19 & 41 & 153 & 194 & 486 \\
\hline Psychodopygus & & & & & & & & & & & & & & & \\
\hline sp. & 一 & - & - & 一 & 一 & 一 & 一 & 一 & 一 & - & - & - & 1 & 1 & 1 \\
\hline $\mathbf{T}$ & 110 & 3 & 113 & 3,2 & 193 & 6 & 199 & 5,7 & 5 & 15 & 20 & 46 & 156 & 202 & 534 \\
\hline
\end{tabular}

* Médias horárias (MH) calculadas para as coletas com isca humana com o total de 35 horas/homem. 
FORATTINI, O. P. et al. - Observações sobre a transmissão de leishmaniose tegumentar no Estado de São Paulo, Brasil. Rev. Saúde públ., S. Paulo, 10:31-43, 1976.

\section{T A BELA 3}

Resultados das coletas mensais de flebotomineos no ambiente domiciliar da Fazenda Jatai (fevereiro a novembro de 1973)."

\begin{tabular}{|c|c|c|c|c|}
\hline \multirow{2}{*}{ Meses (1973) } & \multicolumn{4}{|c|}{ Psychodopygus intermedius } \\
\hline & 우우 & $0^{*} 0^{\circ}$ & $\mathbf{T}$ & $\mathrm{MH}$ \\
\hline fevereiro & 552 & 17 & 569 & 47,4 \\
\hline março & 112 & 1 & 113 & 9,4 \\
\hline abril & 1 & 一 & 1 & - \\
\hline maio & 311 & 12 & 323 & 27,0 \\
\hline junho & 33 & 一 & 33 & 2,7 \\
\hline julho & 268 & 8 & 276 & 23,0 \\
\hline agosto & 97 & 6 & 103 & 8,6 \\
\hline setembro & 155 & 1 & 156 & 13,0 \\
\hline outubro & 173 & 8 & 181 & 15,0 \\
\hline novembro & 131 & 9 & 140 & 11,7 \\
\hline $\mathbf{T}$ & 1833 & 62 & 1895 & 15,8 \\
\hline
\end{tabular}

* Médias horárias $(\mathrm{MH})$ calculadas com 12 horas/homem para cada mês com o total de 120 horas/homem trabalhadas. Valores apresentados a partir de 0,1.

T A B EL A 4

Resultados das coletas de flebotomíneos no ambiente florestal do Bairro de são Lourencinho (outubro 1973 a novembro 1974).*

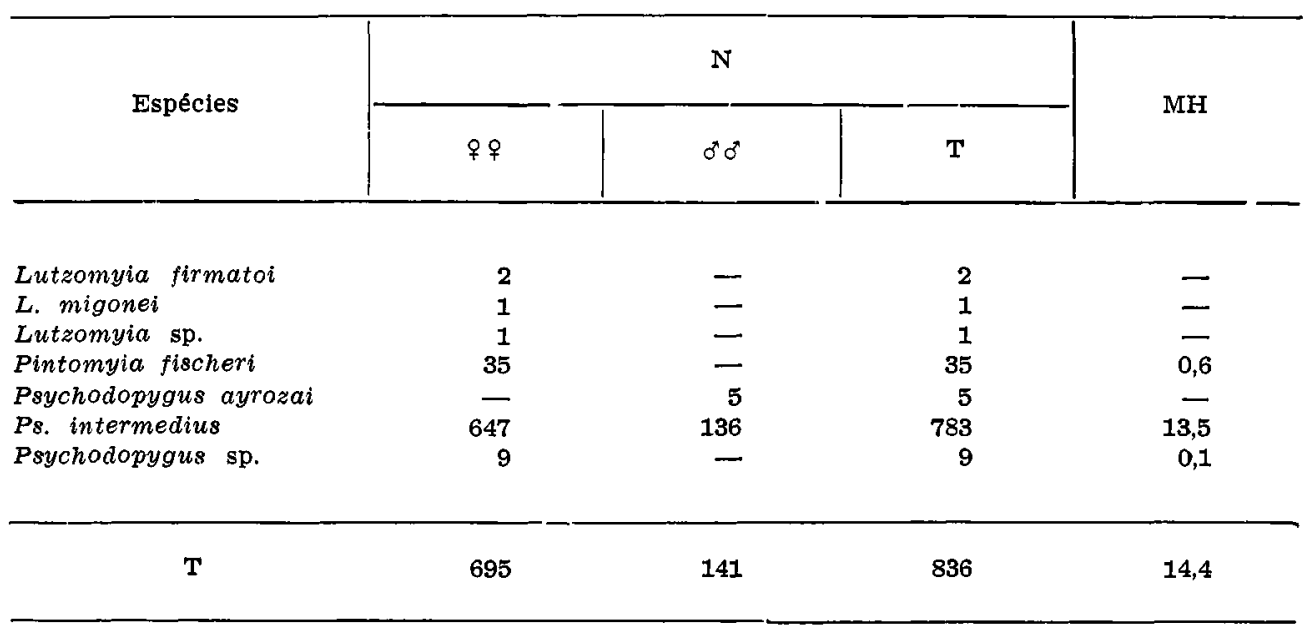

* Médias hoŕ́rias ( $\mathrm{MH})$ calculadas com o total de 58 horas/homem. Valores apresentados a partir de 0,1. 


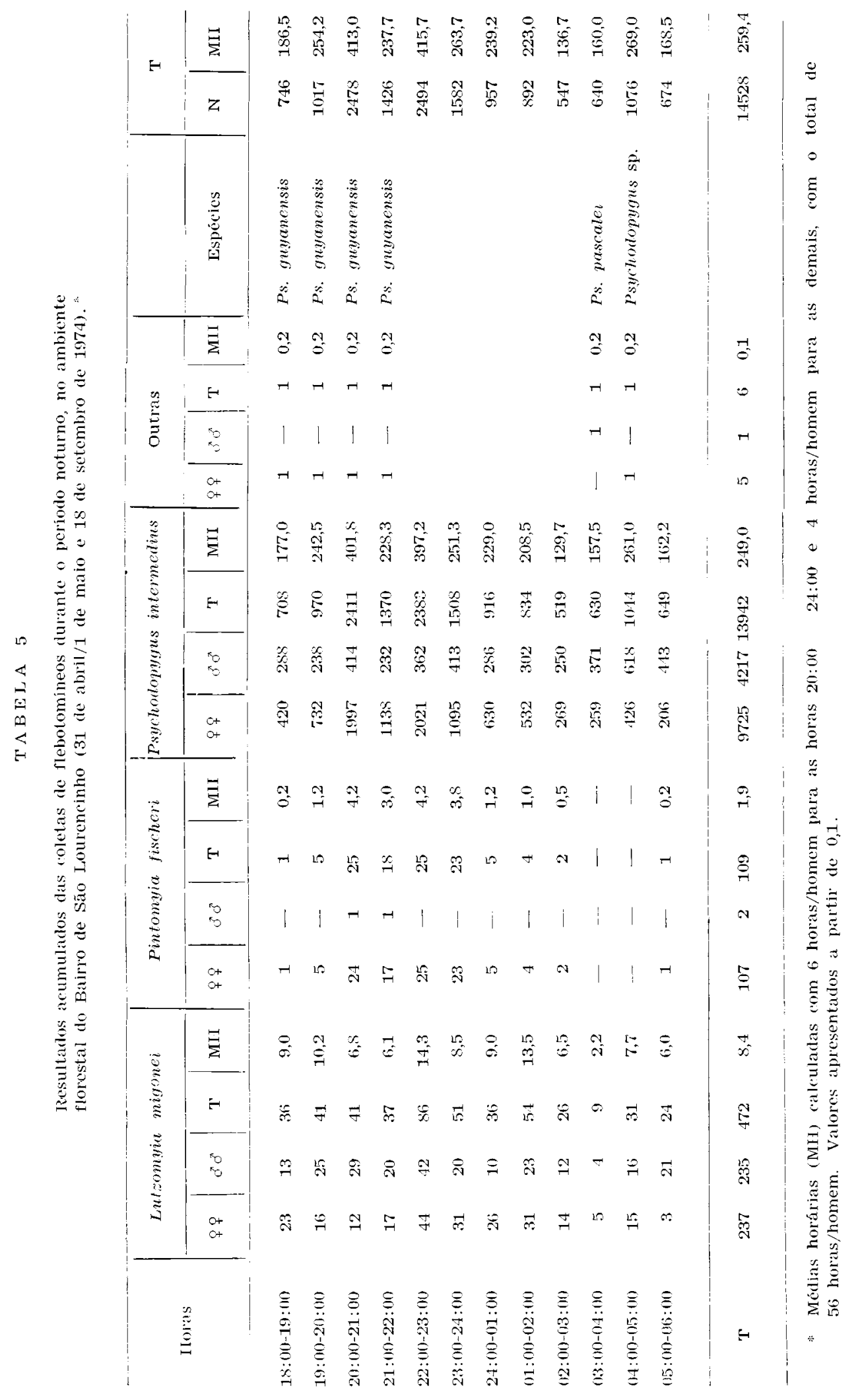


FORATTINI, O. P. et al. - Observações sobre a transmissão de leishmaniose tegumentar no Estado de São Paulo, Brasíl. Rev. Saúde públ., S. Paulo, 10:31-43, 1976.

T A BELA 6

Resultados das coletas de flebotomineos nos ambientes domiciliar e peridomiciliar, do Bairro de São Lourencinho (outubro 1973 a setembro 1974). *

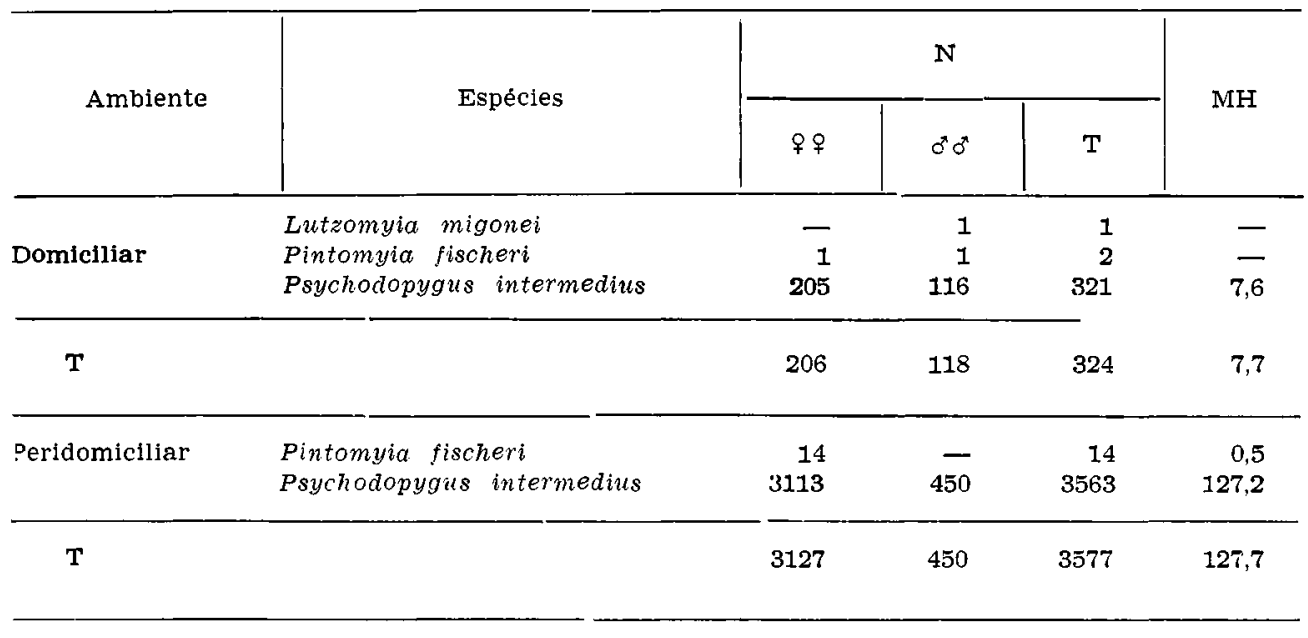

* Médias horárias (MH) calculadas com os totais de 42 horas/homem para o ambiente domiciliar e de 28 horas/homem para o peridomiciliar. Valores apresentados a partir de 0,1 .

realizadas com armadilha tipo Shannon que, a rigor, não representa abrigo satisfatório para o flebotomíneo. Assim sendo, com o advento do período da madrugada e da conseqüente queda de temperatura, o inseto teria tendência a procurar seus esconderijos naturais daí resultando menor comparecimento na captura. Por sua vez, no ambiente domiciliar, as formas adultas poderiam encontrar abrigo viável, motivo pelo qual tenderiam a invadir as casas mesmo nas horas menos favoráveis à sua atividade. De qualquer forma, esse aspecto é fortemente sugestivo da capacidade da população local de $P_{s}$. intermedius freqüentar as habitações e, em conseqüência, entrar em contato com a população humana.

Face aos dados obtidos pelas observações em ambos os focos, tudo parece indicar que, pelo menos no período em que foram levadas a efeito, a população local de Psychodopygus intermedius deva ser responsabilizada pela transmissão da leish- maniose tegumentar humana. Além de sua infecção natural, já constatada em outras ocasiōes, há que se levar em consideração o seu comportamento (Forattini e Santos, $1952^{2}$, Forattini e col. ${ }^{5}, 1972$ ). Com efeito, mostrou-se como sendo a espécie francamente dominante sobre os demais flebotomíneos, nos vários tipos de coleta empregados. É bem verdade que a composição específica dessa fauna encontra-se sujeita a sensíveis variações, de acordo com numerosos fatores ainda não bem conhecidos. Esse fenômeno tem sido verificado em outras oportunidades, quando da realização de observações por tempo mais prolongado (Forattini ${ }^{1}, 1960$ ). Não obstante, na época em que os atuais estudos foram levados a efeito, houve ocorrência de transmissão ativa da doença evidenciada pelo aparecimento de casos recentes. Esse fato, aliado à dominância constatada do Ps. intermedius, parece constituir associação bastante sugestiva. Acresce que esse predomínio manteve-se 


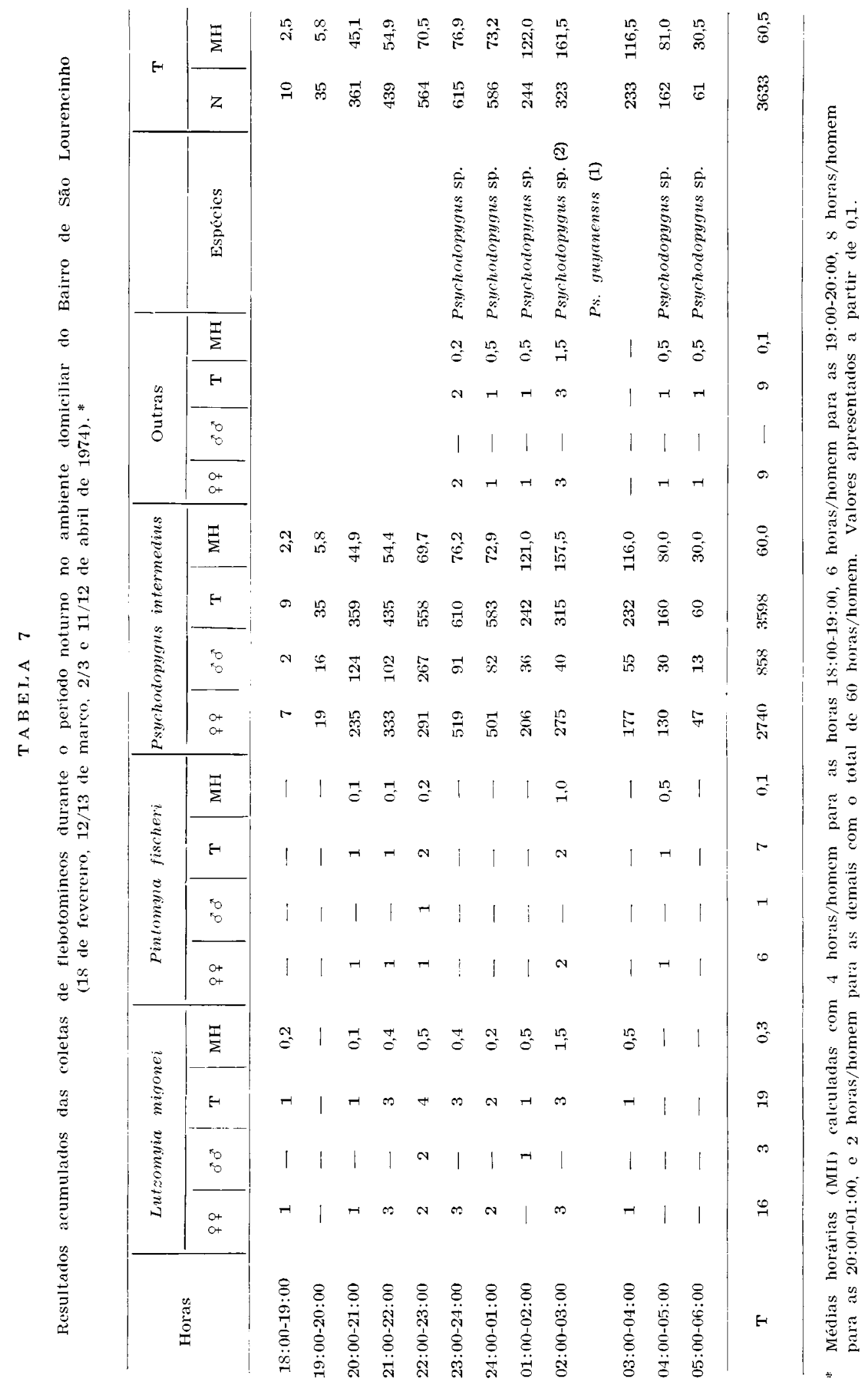


FORATTINI, O. P. et al. - Observações sobre a transmissão de leishmaniose tegumentar no Estado de São Paulo, Brasil. Rev. Saúde públ., S. Paulo, 10:31-43, 1976.

constante em várias situações do ambiente florestal de ambos os focos estudados.

Mais sugestivo ainda, como se mencionou, foram os resultados das coletas domiciliares. Elas vieram mostrar não apenas a tendência desse inseto em invadir as casas, como também o de ali procurar abrigo. Com efeito, observando-se o gráfico representado na Fig. 1, pode-se notar certo antagonismo na segunda metade da noite, em relação aos resultados da armadilha de Shannon na floresta e as capturas nas casas. Não será demais ressaltar esse aspecto já mencionado em parágrafo anterior e que induz à hipótese da existência de apreciável cota domiciliar no quadro local da veiculação dessa protozoose.

Tal fato já tinha sido entrevisto, em outras ocasiôes, em áreas da baixada litorânea fluminense, lançando assim a suspeita da responsabilidade desse flebotomíneo (Nery-Guimarães $\left.{ }^{8}, 1955\right)$. Isso leva forçosamente a admitir que, a desinsetização das habitações, incluindo os seus anexos, possa trazer benefícios pela eliminação desse contingente que, ao que tudo indica, é bastante significativo. Nesse particular, algumas experiências anterior- mente levadas a efeito, na mesma região mencionada do Estado do Rio de Janeiro, têm fornecido resultados promissores (Nery-Guimarães e Bustamante $\left.{ }^{9}, 1954\right)$.

\section{CONCLUSOES}

Face ao apresentado no texto precedente, é lícito concluir o que se segue:

1 - Nos focos estudados dos municípios de Luís Antônio e Pedro de Toledo, no Estado de São Paulo, houve total dominância da espécie Psychodopygus intermedius.

2 - Tal fato, aliado ao seu comportamento antropófilo e domiciliar, autoriza a estabelecer associação entre a atividade desse flebotomíneo e a transmissão local da leishmaniose tegumentar.

3 - A freqüência desse díptero ao domicílio e peridomicílio sugere que parte significante da transmissão se faça nesses ambientes.

4 - Face a isso, a adoção de medidas profiláticas baseadas na aplicação de inseticidas residuais nas habitações, é indicada para interromper essa transmissão.

RSPU-B/297

ForatTini, O. P. et al. - [Transmission of cutaneous leishmaniasis in the State of S. Paulo, Brazil]. Rev. Saúde públ., 10:31-43, 1976.

SUMMARY: Investigations were made in two foci of cutaneous leishmaniasis of the State of $\mathrm{S}$. Paulo, Brazil, on the phlebotominae role regarding the local transmission. Data obtained identified the Psychodopygus intermedius as the species involved in the transmission of the disease. This species was frequently present in human dwellings which allows us to suggest the use of chemical insecticides inside houses as a good prophylactic measure.

UNITERMs: Cutaneous leishmaniasis. Transmission. Psychodopygus intermedius. Phlebotominae (behaviour, houses invasion). Epidemiology. 
FORATTINI, O. P. et al. - Observações sobre a transmissão de leishmaniose tegumentar no Estado de São Paulo, Brasil. Rev. Saúde pübl., S. Paulo, 10:31-43, 1976.

\section{REFERENCIAS BIBLIOGRAFICAS}

1. FORATTINI, O. P. -- Novas observaçc̃es sobre a biologia de flebótomos em condiçōes naturais (Diptera, Psychodidae). Arq. Hig., S. Paulo, 25:209$15,1960$.

2. FORATTINI, O. P. \& SANTOS, M. R. dos - Nota sobre a infecção natural de Phlebotomus intermedius Lutz e Neiva, 1912, por formas em leptomonas, $\mathrm{em}$ um foco de leishmaniose tegumentar americana Arq. Hig., S. Pau10, $17: 171-4,1952$.

3. FORATTINI, O. P. et al. - Nota sobre um foco de leishmaniese tegumentar na região nordeste do Estado de São Paulo, Brasil. Rev. Saúde púlbl., $\mathrm{S}$. Paulo, 6:103-5, 1972.

4 FORATTINI, O P. et al - Infeçōes naturais de mamiferos silvestres em área endêmica de leishmaniose tegumentar do Estado de São Paulo, Brasil. Rev. Saude pübl., S. Paulo, 6: $25 \tilde{5} \cdot 61,1972$.

5. FORATTINI, O. P. et al - Infecção natural de flebotomineos em foco enzoótico de leishmaniose tegumentar no Estado de São Paulo, Brasil. Rev. Saíde publ., S. Paulo, 6:431-3, 1972
6. FORATTINI, O. P. et al - Nota sobre infecção natural de oryzomys capito laticeps em foco enzoótico de leishmaniose tegumentar no Estado de São Paulo, Brasil. Rev. Saúde puibl., $\mathrm{s}$. Paulo, 7:181-4, 1973.

7. FORATTINI, O P. et al. - Nota sobre leishmaniose tegumentar no litoral sul do Estado de São Paulo, Brasil. Rev. Saúde puibl., S Paulo, $7: 447-52$, $197 \mathrm{~s}$.

8. NERY-GUIMARAES, F. - Estudo de um foco de leishmanlose muco-cutânea na baixada fluminense (Estado do Rio de Janeiro). Mem. Inst. Oswaldo Cruz, $53: 1-11,1955$.

9. NERY-GUIMARAES, F. \& BUSTAMANTE, F. M. de - A aplicação domiciliária de DDT como base da profilaxia das leishmanioses. Estudo de um foco de leishmaniose muco-cutânea cinco anos depois da aspersão periódica com aquele inseticida. Rev. bras. Malar., $6: 125-30,1954$.

Recebido para publıcação em 08/12/1975

Aprovado para publicação em $05 / 01 / 1976$ 